DOI: 10.31695/IJASRE.2021.34123

\title{
Pharmacogenomics: History, Development and Challenges
}

\author{
Aditi Ranade \\ Student \\ Bombay College of Pharmacy \\ Mumbai, India
}

\begin{abstract}
Pharmacogenomics is seen as the combination of pharmacology and genomics. It studies the effect of genetic variations and genetic polymorphisms on the drug response. Individuals respond differently to drugs and sometimes the effects are unpredictable. Differences in DNA that alter the function or expression of proteins that are targeted by drugs can contribute notably to variation in the responses of individuals. This intersection of genomics and medicine has the capacity to yield a new set of molecular diagnostic tools which can be used to optimize drug therapy. By optimizing drug therapy, reducing adverse drug reaction events, and developing patient-centric approaches, pharmacogenomics can achieve the goal of personalized medicine wherein the right drug or right amount of drug is given to the right patient. The present article sheds light upon the historical perspective of pharmacogenomics and the seminal studies examining the fact that patients do not uniformly respond to medications. It also emphasizes the current status of pharmacogenomics and drug development. Some of the barriers in implementing pharmacogenomics have also been presented.
\end{abstract}

Key Words: Pharmacogenomics, Adverse drug reactions, Drug Development, Personalized Medicine, Pharmacogenomic Testing

\section{INTRODUCTION}

Pharmacogenomics essentially refers to the altered drug response due to genetic variations in an individual. The term "Pharmacogenetics" was first coined by Friedrich Vogel in 1959.1 In the late 1990s, with advancements in DNA technology and genomic sciences, "pharmacogenomics" a newer term was introduced [1]. Both terms are used interchangeably, with pharmacogenetics alluding to the study of individual gene-drug interactions whereas Pharmacogenomics is a comprehensive term for investigating genomic influence on drug response, using high-throughput techniques such as expression profiling, sequencing, single nucleotide polymorphism chip, and proteomics [20]. It identifies genetic factors and their contribution to the interindividual variability in drug efficacy and toxicity. Genetic variations in drug metabolism were first discerned by noticing the very high or very low concentrations of the drug found in some patients despite administrating the same amount of the drug [3]. Variability in drug response arises due to several reasons; the inability of selected drug therapy to target the underlying mechanism which might or might not be known, diseased conditions, drug interactions, lack of compliance, improper drug delivery, changes in the dose are often quoted $[4,5]$. However, the genetic architecture of an individual plays a chief role in determining the drug response. Genetic variations influence drug response and can elicit differences in drug response that varies from potentially life-threatening adverse drug reactions at one end of the spectrum, to a lack of desired therapeutic effect at the other end [6,7]. The essence and effectiveness of personalized medicine could possibly circumvent these differences and facilitate the development of personalized therapy to maximize drug efficacy and minimize drug toxicity. From discovering adverse drug reactions due to inherited genetic deficiencies to the present genome-wide approaches assessing genetic variation in multiple genes, the convergence of rapid developments in pharmacogenomics has furnished a pioneering opportunity to move towards the goal of developing truly individualized drug therapy [8]. The concomitant study of the human genome project and the HapMap project has allowed pharmacogenomics to ascertain the altered drug metabolism seen in individuals and specific types of populations $[9,10]$.

\section{Why Pharmacogenomics?}

The potential therapeutic effects of pharmacogenomics are immense, and they will minimize the likelihood of adverse pharmacological effects in a patient [11]. The one-size-fits-all model will not provide effective treatment to patients is perspicuous. Doctors will be able to provide optimal and safe therapies to the patients if they have accurate and reliable 


\section{International Journal of Advances in Scientific Research and Engineering [ijasre], Vol 7 [12], December -2021}

pharmacogenomic data. The critical considerations in the field of pharmacogenomics include pharmacokinetics and pharmacodynamics [12]. Polymorphisms in drug metabolizing enzymes ultimately reflect the pharmacokinetics and pharmacodynamics aspects of an individual [13]. Predicting the adverse drug reactions contingent on the above aspects is the priority of pharmacogenomics. The ultimate promise of pharmacogenomics is to improve patient outcomes and reduce overall health costs.[14,15] For instance, Clopidogrel [antiplatelet agent] is bioactivated by CYP2C19 [16]. It has been manifested those individuals having CYP2C19 loss-of-function allele show a decreased response to the drug consequently increasing the incidence of adverse cardiac events compared with non-carriers [17]. Therefore the appropriate dosing recommendations derived from the elucidation of CyP2C19 genotype for clopidogrel are distinctly demarcated in the CPIC instruction [18].

The escalating need for pharmacogenetics has been perceived by FDA and FDA has started implementing the pharmacogenomic information into drug labels and provides a list of drugs for which biomarkers are encompassed in the labeling [19]. Also, the labels provide certain actions which can be carried based on the biomarkers. Moreover, a growing number of institutions have started to develop clinical services and infrastructures to facilitate pharmacogenomic research, analysis, and testing [20] [21]. Although there are numerous challenges to bringing pharmacogenomics into routine clinical practice, the coming years will witness this new paradigm of "Personalized Medicine".

\section{HISTORY OF PHARMACOGENOMICS}

In early $510 \mathrm{BC}$, the Greek Philosopher and mathematician Pythagoras first noted the adverse response when he observed that certain Mediterranean populations developed favism, a form of hemolytic anemia and jaundice ensuring the intake of fava beans and other legumes [22]. It was later discovered that favism was a result of a hereditary abnormality leading to deficiency of the red cell enzyme Glucose-6- phosphate dehydrogenase [G6PD] [23]. The prior probing and pioneer studies include the establishment of rules of heredity by Mendel in 1866, Characterization of the 'phenylthiourea nontaster' as an autosomal recessive trait in 1932 [24], and ascertainment of sensitivity to the hemolytic effect upon the administration of primaquine, an antimalarial drug was due to intrinsic defect in erythrocyte leading to deficiency of G6PD enzyme during World War 2 [25-27]. All these studies were summarized and revised by Dr. Arno Motulsky and he published a paper titled 'Drug reactions, enzymes, and biochemical genetics' in 1957 [28]. The 20th century profusely witnessed numerous research being conducted on various drugmetabolizing enzymes and assessing the contribution of the various genetic components to the overall response to a drug $[29,30]$. In the 1960s Karlow demonstrated the prolonged response to the muscle relaxant succinylcholine causing apnea and long muscle paralysis due to a genetically determined defect in Butyrylcholinesterase [pseudocholinesterase] which inactivates succinylcholine in a few minutes [31]. His other influential studies lead to the publication of the book "Pharmacogenetics: Heredity and the Response to Drugs" in 1962 underlying the significance of interindividual variations in drug response [32]. In 1962, Vogel coined the term 'Pharmacogenomics'. Another seminal study includes the illustration in the polymorphism in human NAT [N-acetyl transferase] enzyme relevant in the pharmacokinetics of drugs like hydralazine [hypertensive] and isoniazid [antitubercular] by Price Evans [33]. This is majorly found in Caucasian populations [34]. He found out that there are two variants of the human NAT isoenzymes now known as NAT1 and NAT2 which catalyzes N acetylation and O-acetylation of heterocyclic amines and arylamines [35]. 'Slow acetylations and "fast acetylations aroused from the polymorphism in NAT affected the Pharmacokinetics of certain drugs [36]. Slow acetylators lead to high plasma levels of drugs such as hydralazine and isoniazid which enhanced their toxicity whereas the fast acetylators showed an altered response to the treatment than anticipated. In 1988, The polymorphism in debrisoquine hydroxylase now known as CYP2D6 was another pertinent observation in the metabolism of debrisoquine and sparteine [37,38]. Gonzalez and Meyer cloned the enzyme and characterized the defect in it [39-41]. Subsequently, it was found out that certain individuals were referred to as poor metabolizers and rapid metabolizers [42,43]. The toxicity of the drug was increased in PMs whereas the efficacy of the drug was decreased in RMs $[40,42,43]$. 


\section{CURRENT STATUS OF PHARMACOGENOMICS}

Pharmacogenomic knowledge is being used extensively to develop tailored drugs to treat a wide range of health problems. An instance of its application involves patients affected with Human Immunodeficiency Virus [HIV]. Patients who carry the HLA$\mathrm{B} * 5701$ variant are susceptible to developing an adverse hypersensitivity reaction to the drug abacavir [52,53]. Hence, before prescribing abacavir, doctors routinely test for the variant and the drug is contraindicated if the test is positive [54]. It has been recommended by FDA that doctors should test colon cancer patients for certain genetic variants before administering irinotecan [Camptosar], which is part of a combination chemotherapy regimen [55,56]. Another instance is the drug trastuzumab used to treat breast cancer. This therapy is effective in women whose tumors possess a specific genetic profile which leads to overproduction of HER2 protein [57,58]. Genetic testing of the patients before administrating mercaptopurine, a chemotherapy drug to be used to treat acute lymphoblastic leukemia is recommended by FDA $[50,59,60]$. The aim of pharmacogenomics is to elucidate the gene-drug interaction, to find out the genetic variants responsible for the lack of desired response, and to deliver efficacious therapies [61,62].

Table1. Pharmacogenomics: Seminal Studies

\begin{tabular}{|c|c|c|c|c|}
\hline Drug & Altered Clinical Effect & $\begin{array}{l}\text { Gene } \\
\text { Responsible }\end{array}$ & Mechanism & Reference \\
\hline Primaquine & Haemolytic Anaemia & G6PD & G6PD deficiency & [27] \\
\hline Phenylthiourea & Impotence to taste PTU & TAS2R1 & $\begin{array}{l}\text { PTU non-taste trait, } \\
\text { SNPs in taste } \\
\text { receptor }\end{array}$ & {$[44,45]$} \\
\hline Isoniazid & $\begin{array}{l}\text { Peripheral neuropathy in slow } \\
\text { acetylators }\end{array}$ & NAT2 & $\begin{array}{l}\text { Altered function, } \\
\text { variations in NAT2 }\end{array}$ & {$[46,47]$} \\
\hline Debrisoquine & Poor metabolizers showed ADR & CYP2D6 & CYP2D6 variants & {$[40,48,49]$} \\
\hline Thiopurines & $\begin{array}{l}\text { Myelosuppression in poor } \\
\text { metabolizers }\end{array}$ & TPMT & $\begin{array}{l}\text { TPMT variants } \\
\text { result in reduced } \\
\text { function }\end{array}$ & [50] \\
\hline Succinylcholine & Prolonged muscle paralysis & $\begin{array}{l}\text { Butyrylcholin } \\
\text { esterase }\end{array}$ & $\begin{array}{l}\text { Reduced BChE } \\
\text { activity }\end{array}$ & {$[31,51]$} \\
\hline
\end{tabular}

\section{PHARMACOGENOMICS IN DRUG DISCOVERY}

Remarkable advancements in genome sequencing technology have enabled pharmaceutical companies to formulate futuristic models and suitable computational and informatics studies supporting them [63,64]. Researchers are twice as likely to find a drug target utilizing genomic knowledge and computational support than utilizing old methods [65,66]. The elucidation of drug targets could be improved by genetics by ameliorating the design of clinical trials and as a consequence drugs could possibly get to the market quickly [67,68]. In addition, during clinical trials, it could assist in predicting the drug response based on the personalized testing of variants $[67,69,70]$. Moreover, researchers are engrossed in contriving and validating tests for subsequent clinical applications. Connecting the gene with the disease and obtaining a molecule that can be amended to treat the disease is the preliminary step. [71] The pharmacokinetics and pharmacodynamics of new drugs are well articulated by scrutinizing 
pharmacogenomic studies, and these advancements impact the development of new drugs [30,67]. Targets that succeed during the target validation process are probably genetically validated. Although we have only 10 to 15 percent of targets that possess genetic data on them, and they ultimately result in the reduction of cost [70,72]. This can be achieved by interpreting human genetics and by outlining less expensive clinical trials $[33,73]$. The therapeutic risk and benefit ratio is improved by decreasing side effects in patients during clinical trials [1,73,74]. Clinical shreds of evidence for research and drug development and all the needful information are offered by pharmacogenomic studies to proceed into the next steps of the process [64,73,74]. Scientists will thus be able to determine the most responsive patients and will make the drug development process more reliable. Hence, scientists are adapting to this new paradigm which works towards the development of precision medicine $[75,76]$.

\section{PHARMACOGENOMICS, DRUG DEVELOPMENT, AND FDA}

As a part of the drug development process, the pharmacogenetic data submitted by the pharmaceutical companies should adhere to the guidelines provided by FDA [77]. However, most of the results are not scientifically well-delineated hence they cannot be employed for regulatory agreements by FDA. In addition, at the time of submitting the absolute pharmacogenetic report and a truncated report, it should comply with the guidelines which have also been released associated with it [60]. Moreover, separate guidelines are there for the submission of pharmacogenetic data for investigational new drug applications and unapproved and approved marketing applications [60,64]. As mentioned above, a well-expounded pharmacogenetic test is necessary as a valid biomarker for making regulatory decisions by the FDA [19,60,64,78]. The acceptance of a pharmacogenetic test as a valid biomarker requires an articulated scientific framework and prominent characteristics [79]. Drug metabolizing enzymes [markers for drug efficacy and safety] is a good example of a valid biomarker in pharmacogenetic tests [80,81]. For instance, patients having variant alleles of the gene CYP2C9 and VKORC1 require fewer doses of warfarin, as compared to patients having normal wild-type alleles $[82,83]$. This is considered a valid biomarker and pharmacogenomic data has been subsumed in the drug label for warfarin $[24,84-86]$.

\section{CHALLENGES AND IMPLEMENTATION OF PHARMACOGENOMICS}

Pharmacogenomic testing has been incorporated into clinical practice but at a slower pace compared to the evolving advancements in genetic research [76,87-92]. Many organizations and companies are trying to integrate and execute the pharmacogenomic testing of patients to provide them personalized therapy [93]. Some organizations have succeeded in implementing pharmacogenomics and are paving way for others. To mention a few, St. Jude hospital in the United States has been the lead hospital to implement pharmacogenomics since the 1990s [94]. They conduct Pharmacogenomics for kids' program [PG4KDS] to set up processes for using pharmacogenetic tests in the electronic health record [EHR] to preventively guide prescribing [94]. Other hospitals conduct pharmacogenomic testing of only those drugs that are prominent to adverse drug events [ADE] [20,95]. Interdisciplinary clinicians discuss the results of the pharmacogenomic test [genetic test ordered by an authorized physician before beginning the drug therapy [20,95-97].

\subsection{CHALLENGES TO PHARMACOGENOMIC RESEARCH AND TESTING}

Even though pharmacogenomics is anticipated to ascertain the right drug at the right dose during the pharmacotherapy by identifying individuals at risk and reducing adverse events, its appropriate use in clinical uptake, and its implementations in medical and pharmacy practice is an important issue [98,99]. Implementing pharmacogenomic testing in a clinical setting is very elusive and has to face many challenges. Some key challenges are included below: 


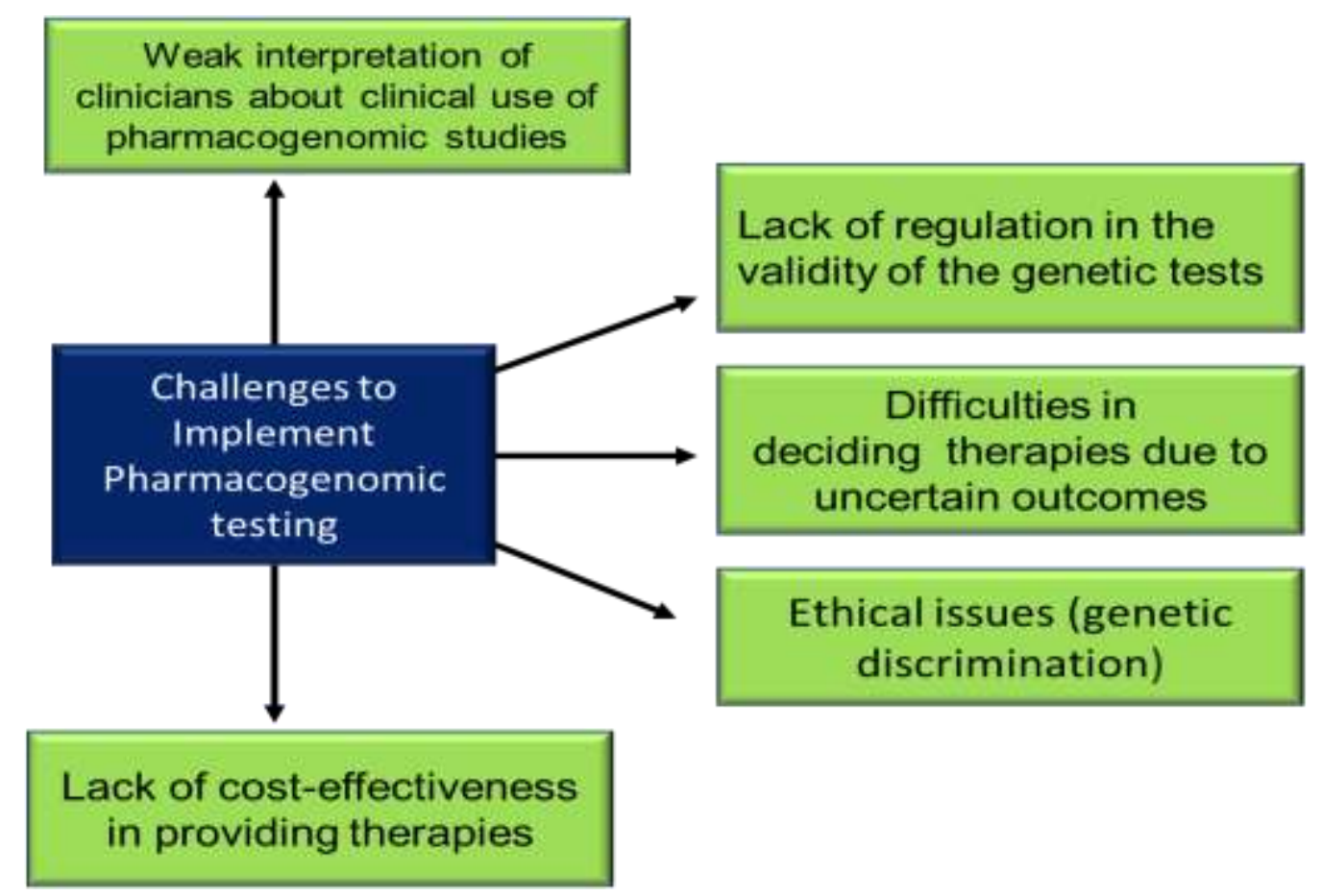

Figure 1: Challenges to implement Pharmacogenomic testing [69,76,95,98,100,101]

Clinicians should have a coherent understanding of the clinical utility of genetic testing. The application of genetic principles is used to guide therapeutic decisions [102-104]. It can be applied directly to patient outcomes by increasing the efficacy and reducing the toxic effects of the drug. Although this approach requires the creation and elaboration of guidelines that will provide substantial clarification of pharmacogenomic testing. To facilitate and implement pharmacogenomic testing for patient care and personalized therapy, we have Clinical Pharmacogenetics Implementation Consortium [CPIC] is an international association that publishes genotype-based drug guidelines assisting clinicians to understand how optimized drug therapy can be achieved using available genetic test results [105-107].

It was established in 2009 and it is an association between The Pharmacogenomics knowledge base [PharmGKB] and the Pharmacogenomics Research Network [PGRN] [106,108,109] and which alleviates complications in clinical implementation in healthcare by imparting guidelines of how to use pharmacogenomic knowledge.

\subsection{CHALLENGES TO PHARMACOGENOMIC RESEARCH}

Despite the potential of the conduction of pharmacogenomics research in enhancing the effectiveness development of treatment strategies for patients is encouraged, such research is a complicated and challenging task owing to the following factors mentioned in the figure. Further challenges in basic research concern a variety of additional influential factors that need to be addressed more systematically such as management \& uniform representation of data, reproducibility, analysis, regulation, etc which pharmacogenomics has to overcome [89,113]. The influence of numerous non-genetic end environmental factors, including sex, age, diet, lifestyle is relevant [98]. Pharmacogenomics is on its way to executing "Personalized Medicine". However, pharmacogenomics is facing several challenges including ethical problems in its way. If the ethical problems are not resolved and undiagnosed then the improvement and amplification of personalized medicine are very elusive. In this regard, there is various research aiming at resolving ethical issues in two fields of research and development and service provision to suggest and create some solutions [114-117]. 


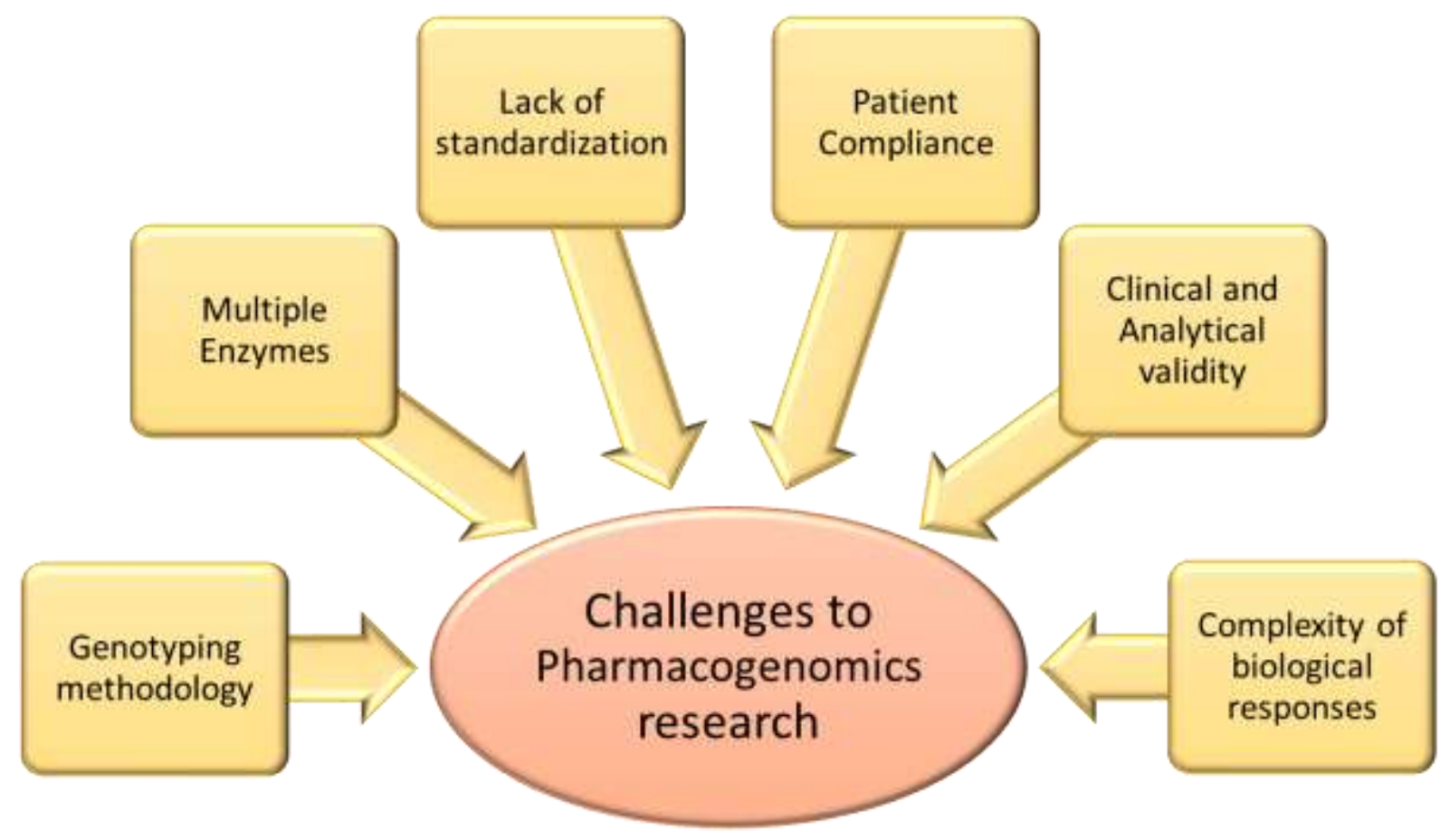

Figure 2. Challenges to implement Pharmacogenomic testing [14,110-112]

\section{CONCLUSION}

Pharmacogenomics in the pharmaceutical industry is a potential \& promising tool, awaiting use for the maximum benefit \& outcome. Currently, pharmacogenetic methods are being used worldwide, especially for assessing the safety profile of drugs. Pharmacogenomics has advanced our understanding of complex pathology, drug response, adverse drug effects, and targeted therapeutics Pharmacogenomics can facilitate the development of tailored drugs to treat a wide variety of diseases including cardiovascular disorders, cancer, asthma, AIDS. The gradual inclusion of pharmacogenomic studies in drug discovery and development will create a substantial reduction in the expenses involved in drug development, ensure a safe clinical trial and reduce failures with more accurate results. Pharmacogenomics can be implemented routinely with the help of evolving technologies and overcoming the barriers to it. The clinical implementation of pharmacogenomic research and testing ultimately depends on the robustness of cost-benefit analysis and the overall outcome and benefit of public health.

Pharmacogenomics is leading the way to develop rational means to optimize drug therapy, with respect to the patients' genotype to ensure maximum efficiency with a minimal adverse effect so that the right amount of drug is given to the right patient. It offers unprecedented opportunities to develop effective drug development and has the capacity to revolutionize patient-centric drug therapy approaches.

\section{REFERENCES}

1. Nebert DW, Zhang G. 16 - Pharmacogenomics. In: Pyeritz RE, Korf BR, Grody WW, editors. Emery and Rimoin's Principles and Practice of Medical Genetics and Genomics [Seventh Edition] [Internet]. Academic Press; 2019 [cited 2021 Dec 14]. p. 44586. Available from: https://www.sciencedirect.com/science/article/pii/B9780128125373000160

2. Pirmohamed M. Pharmacogenetics and pharmacogenomics. Br J Clin Pharmacol. 2001 Oct;52 [4]:345-7.

3. Somogy A. Evolution of pharmacogenomics. Proc West Pharmacol Soc. 2008;51:1-4.

4. Alomar MJ. Factors affecting the development of adverse drug reactions [Review article]. Saudi Pharm J SPJ. 2014 Apr;22[2]:83-94. 


\section{International Journal of Advances in Scientific Research and Engineering [ijasre], Vol 7 [12], December -2021}

5. Marchant B. Pharmacokinetic factors influencing variability in human drug response. Scand J Rheumatol Suppl. 1981;39:514.

6. Roden DM, Wilke RA, Kroemer HK, Stein CM. Pharmacogenomics: The genetics of variable drug responses. Circulation. 2011 Apr 19;123[15]:1661-70.

7. Cacabelos R, Cacabelos N, Carril JC. The role of pharmacogenomics in adverse drug reactions. Expert Rev Clin Pharmacol. 2019 May;12[5]:407-42.

8. Kalow W. Human pharmacogenomics: The development of a science. Hum Genomics. 2004 Aug 1;1[5]:375.

9. O’Shaughnessy KM. HapMap, pharmacogenomics, and the goal of personalized prescribing. Br J Clin Pharmacol. 2006 Jun;61[6]:783-6.

10. Zhang W, Ratain MJ, Dolan ME. The HapMap Resource is Providing New Insights into Ourselves and its Application to Pharmacogenomics. Bioinforma Biol Insights. 2008 Feb 1;2:15-23.

11. Gupta PD. Pharmacogenetics, Pharmacogenomics and Ayurgenomics for Personalized Medicine: A Paradigm Shift. Indian J Pharm Sci. 2015;77[2]:135-41.

12. Franconi F, Campesi I. Pharmacogenomics, pharmacokinetics and pharmacodynamics: interaction with biological differences between men and women. Br J Pharmacol. 2014 Feb;171[3]:580-94.

13. Ahmed S, Zhou Z, Zhou J, Chen S-Q. Pharmacogenomics of Drug Metabolizing Enzymes and Transporters: Relevance to Precision Medicine. Genomics Proteomics Bioinformatics. 2016 Oct;14[5]:298-313.

14. Pharmacogenomics: The Right Drug to the Right Person [Internet]. [cited 2021 Dec 14]. Available from: https://www.ncbi.nlm.nih.gov/pmc/articles/PMC3299179/

15. Ross S, Anand SS, Joseph P, Paré G. Promises and challenges of pharmacogenetics: an overview of study design, methodological and statistical issues. JRSM Cardiovasc Dis. 2012 Apr 5;1[1]:cvd.2012.012001.

16. Clopidogrel pharmacogenomics and risk of inadequate platelet inhibition: US FDA recommendations | Pharmacogenomics [Internet]. [cited 2021 Dec 14]. Available from: https://www.futuremedicine.com/doi/10.2217/pgs.09.143

17. Dean L. Clopidogrel Therapy and CYP2C19 Genotype. In: Pratt VM, Scott SA, Pirmohamed M, Esquivel B, Kane MS, Kattman BL, et al., editors. Medical Genetics Summaries [Internet]. Bethesda [MD]: National Center for Biotechnology Information [US]; 2012 [cited 2021 Dec 14]. Available from: http://www.ncbi.nlm.nih.gov/books/NBK84114/

18. Scott SA, Sangkuhl K, Gardner EE, Stein CM, Hulot J-S, Johnson JA, et al. Clinical Pharmacogenetics Implementation Consortium Guidelines for Cytochrome P450-2C19 [CYP2C19] Genotype and Clopidogrel Therapy. Clin Pharmacol Ther. 2011 Aug;90[2]:328-32.

19. Research C for DE and. Table of Pharmacogenomic Biomarkers in Drug Labeling. FDA [Internet]. 2021 Aug 18 [cited 2021 Dec 14]; Available from: https://www.fda.gov/drugs/science-and-research-drugs/table-pharmacogenomic-biomarkers-druglabeling

20. Abul-Husn NS, Owusu Obeng A, Sanderson SC, Gottesman O, Scott SA. Implementation and utilization of genetic testing in personalized medicine. Pharmacogenomics Pers Med. 2014;7:227-40.

21. Johnson JA. Pharmacogenetics in clinical practice: how far have we come and where are we going? Pharmacogenomics. 2013 May;14[7]:835-43.

22. Davies P. Favism. Postgrad Med J. 1961 Aug 1;37[430]:477-80. 


\section{International Journal of Advances in Scientific Research and Engineering [ijasre], Vol 7 [12], December -2021}

23. Meletis J. Favism.A brief history from the "abstain from beans" of Pythagoras to the present. Arch Hell Med. 2012 Apr $1 ; 29: 258-63$.

24. Sinha M, Kalim M, Khan A, Siddiqui H, Sayeed U, Wadhwa D, et al. PHARMACOGENOMICS: A STEP AHEAD IN MODERN DAY DRUG DISCOVERY. Int J Adv Eng Sci Res. 2014 Dec 10;1:13-26.

25. Beutler E. Glucose-6-phosphate dehydrogenase deficiency: a historical perspective. Blood. 2008 Jan 1;111[1]:16-24.

26. Kiani F, Schwarzl S, Fischer S, Efferth T. Three-Dimensional Modeling of Glucose-6-phosphate Dehydrogenase-Deficient Variants from German Ancestry. PLoS ONE. 2007 Jul 18;2[7]:e625.

27. Carson PE et al [1956] Enzymatic defi ciency in primaquine-sensitive erythrocytes. Science 124[3220]:484-485.

28. Motulsky AG. Drug reactions enzymes, and biochemical genetics. J Am Med Assoc. 1957 Oct 19;165[7]:835-7.

29. Cecchin E, Stocco G. Pharmacogenomics and Personalized Medicine. Genes. 2020 Jun;11[6]:679.

30. Kalow W. Pharmacogenomics: historical perspective and current status. Methods Mol Biol Clifton NJ. 2005;311:3-15.

31. Kraft JC, Kim J, Schwinn DA, Landau R. A History of Pharmacogenomics Related to Anesthesiology. In: Eger II EI, Saidman LJ, Westhorpe RN, editors. The Wondrous Story of Anesthesia [Internet]. New York, NY: Springer; 2014 [cited 2021 Dec 15]. p. 585-96. Available from: https://doi.org/10.1007/978-1-4614-8441-7_44

32. Kalow W.Pharmacogenetics: Heredity and the Response to Drugs. W.B.Saunders, Philadelphia, PA: London, 1962.

33. Pharmacogenomics: bench to bedside | Nature Reviews Drug Discovery [Internet]. [cited 2021 Dec 15]. Available from: https://www.nature.com/articles/nrd1497

34. Gu J, Liang D, Wang Y, Lu C, Wu X. Effects of N-acetyl transferase 1 and 2 polymorphisms on bladder cancer risk in Caucasians. Mutat Res. 2005 Mar 7;581[1-2]:97-104.

35. Sim E, Abuhammad A, Ryan A. Arylamine N-acetyltransferases: From Drug Metabolism and Pharmacogenetics to Drug Discovery. Br J Pharmacol. 2014 Jan 28;171.

36. Pharmacogenetics of the arylamine N-acetyltransferases | The Pharmacogenomics Journal [Internet]. [cited 2021 Dec 15]. Available from: https://www.nature.com/articles/6500053

37. Gonzalez FJ et al [1988] Characterization of the common genetic defect in humans defi - cient in debrisoquine metabolism. Nature 331[6155]:442-446.

38. Eichelbaum $\mathrm{M}$ et al [1979] Defective N-oxidation of sparteine in man: a new phar_macogenetic defect. Eur J Clin Pharmacol 16[3]:183-187.

39. Gonzalez FJ, Skoda RC, Kimura S,et al.Characterizationof the common genetic-defect in humans.

40. Skoda, R. C., Gonzalez, F. J., Demierre, A. \& Meyer, U.A. Two mutant alleles of the human cytochrome P-450db1 gene [P450C2D1] associated with genetically deficient metabolism of debrisoquine and other drugs. Proc. Natl Acad. Sci. USA, 1988: 85: 5240- 5243.

41. Distlerath, L. M. et al. Purification and characterization of the human liver cytochromes P-450 involved in debrisoquine 4hydroxylation and phenacetin O-deethylation, two International Journal of Advances in Engineering \& Scientific Research, Volume 1, Issue 8, Dec-2014, pp 13-26. 


\section{International Journal of Advances in Scientific Research and Engineering [ijasre], Vol 7 [12], December -2021}

42. CHANG K-L, WEITZEL K, SCHMIDT S. Pharmacogenetics: Using Genetic Information to Guide Drug Therapy. Am Fam Physician. 2015 Oct 1;92[7]:588-94.

43. Eichelbaum M, Kroemer HK, Mikus G. Genetically determined differences in drug metabolism as a risk factor in drug toxicity. Toxicol Lett. 1992 Dec;64-65 Spec No:115-22.

44. Snyder LH [1932] Studies in human inheri_tance. IX. The inheritance of taste defi ciency in man. Ohio J Sci 32:436-468.

45. Kim UK et al [2003] Positional cloning of the human quantitative trait locus underlying taste sensitivity to phenylthiocarbamide. Science 299[5610]:1221-1225.

46. Harris HW et al [1958] Comparison of iso_niazid concentrations in the blood of people of Japanese and European descent; therapeu_tic and genetic implications. Am Rev Tuberc 78[6]:944-948.

47. Evans DA et al [1960] Genetic control of iso_niazid metabolism in man. Br Med J 2[5197]:485-4.

48. Aklillu, E. et al. Frequent distribution of ultrarapid metabolizers of debrisoquine in an ethiopian population carrying duplicated and multiduplicated functional CYP2D6 alleles. J. Pharmacol. Exp. Ther. 1996: 278: 441-446.

49. Hong-Guang Xie \& Felix W Frueh Pharmacogenomics step towards personalized medicines future Medicine .2005: 325337 .

50. Weinshilboum RM, Sladek SL [1980] Mercaptopurine pharmacogenetics: mono_genic inheritance of erythrocyte thiopurine methyltransferase activity. Am J Hum Genet 32[5]:651-662.

51. Kalow W [1956] Familial incidence of low pseudocholinesterase level. Lancet 271: 576-577.

52. Mallal S, Phillips E, Carosi G, Molina J-M, Workman C, Tomazic J, et al. HLA-B*5701 screening for hypersensitivity to abacavir. N Engl J Med. 2008 Feb 7;358[6]:568-79.

53. Van Den Driessche G, Fourches D. Adverse drug reactions triggered by the common HLA-B*57:01 variant: a molecular docking study. J Cheminformatics. 2017 Mar 4;9:13.

54. Dean L. Abacavir Therapy and HLA-B*57:01 Genotype. In: Pratt VM, Scott SA, Pirmohamed M, Esquivel B, Kane MS, Kattman BL, et al., editors. Medical Genetics Summaries [Internet]. Bethesda [MD]: National Center for Biotechnology Information [US]; 2012 [cited 2021 Dec 15]. Available from: http://www.ncbi.nlm.nih.gov/books/NBK315783/

55. Dean L. Irinotecan Therapy and UGT1A1 Genotype. In: Pratt VM, Scott SA, Pirmohamed M, Esquivel B, Kane MS, Kattman BL, et al., editors. Medical Genetics Summaries [Internet]. Bethesda [MD]: National Center for Biotechnology Information [US]; 2012 [cited 2021 Dec 15]. Available from: http://www.ncbi.nlm.nih.gov/books/NBK294473/

56. Gold HT, Hall MJ, Blinder V, Schackman BR. Cost effectiveness of pharmacogenetic testing for UGT1A1 before irinotecan administration for metastatic colorectal cancer. Cancer. 2009 Sep 1;115[17]:3858-67.

57. Slamon, D. J. et al. Use of chemotherapy plus a monoclonal antibody against HER2 for metastatic breast cancer that overexpresses HER2. N. Engl. J. Med. 344, 783-792 [2001].

58. Eisenhauer, E. A. From the molecule to the clinic — inhibiting HER2 to treat breast cancer. N. Engl. J. Med. 344, 841-842 [2001].

59. Dean L, Kane M. Mercaptopurine Therapy and TPMT and NUDT15 Genotype. In: Pratt VM, Scott SA, Pirmohamed M, Esquivel B, Kane MS, Kattman BL, et al., editors. Medical Genetics Summaries [Internet]. Bethesda [MD]: National Center for Biotechnology Information [US]; 2012 [cited 2021 Dec 15]. Available from:

http://www.ncbi.nlm.nih.gov/books/NBK100660/ 


\section{International Journal of Advances in Scientific Research and Engineering [ijasre], Vol 7 [12], December -2021}

60. Kumar V, Majumdar D. Pharmacogenomics - The New Trend for Personalized Medicine ARTICLE INFO. Indian J Pharm Biol Res. 2016 Jan 1;4:39-49.

61. Crews KR, Hicks JK, Pui C-H, Relling MV, Evans WE. Pharmacogenomics and individualized medicine: Translating science into practice. Clin Pharmacol Ther. 2012 Oct;92[4]:467-75.

62. Becquemont L [June 2009]. "Pharmacogenomics of adverse drug reactions: practical applications and perspectives". Pharmacogenomics. 10 [6]: 961-9. doi:10.2217/pgs.09.37. PMID 19530963.

63. Kuznetsov V, Lee HK, Maurer-Stroh S, et al. How bioinformatics influences health informatics: usage of biomolecular sequences, expression profiles and automated microscopic image analyses for clinical needs and public health. Health Inf Sci Syst 2013; 1: 2 .

64. Surendiran A, Pradhan SC, Adithan C. Role of pharmacogenomics in drug discovery and development. Indian J Pharmacol. 2008 Aug;40[4]:137-43.

65. . Luo Y, Zhao X, Zhou J, et al. A network integration approach for drug-target interaction prediction and computational drug repositioning from heterogeneous information. Nat Commun 2017; 8: 573.

66. Sliwoski G, Kothiwale S, Meiler J, et al. Computational methods in drug discovery. Pharmacol Rev 2014; 66: 334-395.

67. Kraljevic S, Stambrook PJ, Pavelic K. Accelerating drug discovery. EMBO Rep 2004; 5: 837-842.

68. Burt T, Dhillon S. Pharmacogenomics in early-phase clinical development. Pharmacogenomics. 2013 Jul;14[9]:1085-97.

69. Oates J, Lopez D. Pharmacogenetics: An Important Part of Drug Development with A Focus on Its Application. Int J Biomed Investig. 2018;1[2]:111.

70. Cully M. Target validation: Genetic information adds supporting weight. Nat Rev Drug Discov 2015; 14 : 525.

71. Hughes JP, Rees S, Kalindjian SB, et al. Principles of early drug discovery. Br J Pharmacol 2011; 162: $1239-1249$.

72. Thomsen SK, Gloyn AL. Human genetics as a model for target validation: finding new therapies for diabetes. Diabetologia 2017; 60: 960-970.

73. Mestan KK, Ilkhanoff L, Mouli S, et al. Genomic sequencing in clinical trials. J Transl Med 2011; 9: 222.

74. Curtin F, Schulz P. Assessing the benefit:risk ratio of a drug - randomized and naturalistic evidence. Dialogues Clin Neurosci. 2011 Jun;13[2]:183-90.

75. Akhoon N. Precision Medicine: A New Paradigm in Therapeutics. Int J Prev Med. 2021 Feb 24;12:12.

76. Scott SA. Personalizing medicine with clinical pharmacogenetics. Genet Med 2011;13: 987-995.

77. Research C for DE and. Pharmacogenomic Data Submissions [Internet]. U.S. Food and Drug Administration. FDA; 2020 [cited 2021 Dec 17]. Available from: https://www.fda.gov/regulatory-information/search-fda-guidancedocuments/pharmacogenomic-data-submissions

78. Wang B, Canestaro WJ, Choudhry NK. Clinical Evidence Supporting Pharmacogenomic Biomarker Testing Provided in US Food and Drug Administration Drug Labels. JAMA Intern Med. 2014 Dec 1;174[12]:1938-44.

79. Malhotra A. AN INTRODUCTION TO PHARMACOGENOMICS. :12.

80. https://www.nhpf.org/library/background_papers/BP_Pharmacogenomics_01-28-08.pdf. 


\section{International Journal of Advances in Scientific Research and Engineering [ijasre], Vol 7 [12], December -2021}

81. Chadwell K: Clinical practice on the horizon: personalized medicine. Clin Nurse Spec 2013; 27:36-43.

82. Dean L. Warfarin Therapy and VKORC1 and CYP Genotype. In: Pratt VM, Scott SA, Pirmohamed M, Esquivel B, Kane MS, Kattman BL, et al., editors. Medical Genetics Summaries [Internet]. Bethesda [MD]: National Center for Biotechnology Information [US]; 2012 [cited 2021 Dec 17]. Available from: http://www.ncbi.nlm.nih.gov/books/NBK84174/

83. Fung E, Patsopoulos NA, Belknap SM, O’Rourke DJ, Robb JF, Anderson JL, et al. Effect of Genetic Variants, Especially CYP2C9 and VKORC1, on the Pharmacology of Warfarin. Semin Thromb Hemost. 2012 Nov;38 [8]:893-904.

84. Malhotra A. AN INTRODUCTION TO PHARMACOGENOMICS. :12.

85. Gage BF, Lesko LJ. Pharmacogenetics of warfarin: Regulatory, scientific, and clinical issues. J Thromb Thrombolysis $2008 ; 25: 45-51$.

86. Abraham BK, Adithan C. Genetic polymorphism of CYP2D6. Indian J Pharmacol 2001;33:147-69.

87. Roses AD. Pharmacogenetics and the practice of medicine. Nature 2000; 405: 857-865.

88. Chang MT, McCarthy JJ, Shin J. Clinical application of pharmacogenetics: focusing on practical issues. Pharmacogenomics 2015; 16: 1733-1741.

89. McKinnon RA, Ward MB, Sorich MJ. A critical analysis of barriers to the clinical implementation of pharmacogenomics. Ther Clin Risk Manag 2007; 3: 751-759.

90. McPherson E. Genetic diagnosis and testing in clinical practice. Clin Med Res 2006; 4: 123-129.

91. Klein ME, Parvez MM, Shin JG. Clinical Implementation of Pharmacogenomics for Personalized Precision Medicine: Barriers and Solutions. J Pharm Sci 2017; 106: 2368-2379.

92. Nebert DW. Pharmacogenetics and pharmacogenomics: why is this relevant to the clinical geneticist? Clinical Genetics 1999; 56: 247- 258.

93. Malsagova KA, Butkova TV, Kopylov AT, Izotov AA, Potoldykova NV, Enikeev DV, et al. Pharmacogenetic Testing: A Tool for Personalized Drug Therapy Optimization. Pharmaceutics. 2020 Dec 19;12 [12]:1240.

94. RPRD Diagnostics Partners with St. Jude Children's Research Hospital to Offer Comprehensive Pharmacogenetics Testing [2017] In. RPRD Diagnostics, CISION PR Newswire.

95. Arwood MJ, Chumnumwat S, Cavallari LH, et al. Implementing Pharmacogenomics at Your Institution: Establishment and Overcoming Implementation Challenges. Clin Transl Sci 2016; 9: 233-245.

96. Sheffield LJ, Phillimore HE. Clinical use of pharmacogenomic tests in 2009. Clin Biochem Rev. 2009 May;30[2]:55-65.

97. Daly A. Pharmacogenetics: A general review on progress to date. Br Med Bull. 2017 Oct 11;124:1-15.

98. Roden DM, Altman RB, Benowitz NL, Flockhart DA, Giacomini KM, Johnson JA, et al. Pharmacogenomics: Challenges and Opportunities. Ann Intern Med. 2006 Nov 21;145[10]:749-57.

99. Cardon LR, Harris T. Precision medicine, genomics and drug discovery. Hum Mol Genet 2016;25:R166-72.

100. Kroese M, Zimmern RL, Sanderson S. Genetic tests and their evaluation: Can we answer the key questions? Genetics in Medicine 2004; 6: 475-480.

101. Ikediobi ON, Shin J, Nussbaum RL, et al. Addressing the challenges of the clinical application of pharmacogenetic testing. Clin Pharmacol Ther 2009; 86: 28-31. 


\section{International Journal of Advances in Scientific Research and Engineering [ijasre], Vol 7 [12], December -2021}

102. Relling MV, Klein TE. CPIC: Clinical Pharmacogenetics Implementation Consortium of the Pharmacogenomics Research Network. Clin Pharmacol Ther. 2011 Mar;89[3]:464-7.

103. Bertier G, Carrot-Zhang J, Ragoussis V, et al. Integrating precision cancer medicine into healthcare-policy, practice, and research challenges. Genome Med 2016; 8: 108.

104. Agarwal A, Ressler D, Snyder G. The current and future state of companion diagnostics. Pharmgenomics Pers Med 2015; 8: 99-110.

105. Caudle KE, Gammal RS, Whirl-Carrillo M, Hoffman JM, Relling MV, Klein TE. Evidence and resources to implement Pharmacogenetic Knowledge for Precision Medicine. Am J Health-Syst Pharm AJHP Off J Am Soc Health-Syst Pharm. 2016 Dec 1;73[23]:1977-85.

106. Relling MV, Klein TE. CPIC: Clinical Pharmacogenetics Implementation Consortium of the Pharmacogenomics Research Network. Clin Pharmacol Ther. 2011 Mar;89[3]:464-7.

107. Caudle KE, Klein TE, Hoffman JM, Müller DJ, Whirl-Carrillo M, Gong L, et al. Incorporation of Pharmacogenomics into Routine Clinical Practice: the Clinical Pharmacogenetics Implementation Consortium [CPIC] Guideline Development Process. Curr Drug Metab. 2014 Feb;15[2]:209-17.

108. Barbarino JM, Whirl-Carrillo M, Altman RB, Klein TE. PharmGKB: A worldwide resource for pharmacogenomic information. WIREs Syst Biol Med. 2018;10[4]:e1417.

109. Clinical Pharmacogenetics Implementation Consortium [Internet]. [cited 2021 Dec 18]. Available from: https://cpicpgx.org/

110. Scientific Challenges and Implementation Barriers to Translation of Pharmacogenomics in Clinical Practice [Internet]. [cited 2021 Dec 18]. Available from: https://www.hindawi.com/journals/isrn/2013/641089/

111. Chan CWH, Law BMH, So WKW, Chow KM, Waye MMY. Pharmacogenomics of breast cancer: highlighting CYP2D6 and tamoxifen. J Cancer Res Clin Oncol. 2020 Jun;146[6]:1395-404.

112. Fig. 6.2 The current challenges and barriers to clinical implementation... [Internet]. ResearchGate. [cited 2021 Dec 18]. Available from: https://www.researchgate.net/figure/The-current-challenges-and-barriers-to-clinical-implementation-ofpharmacogenomics_fig2_236117731

113. Challenges in pharmacogenomics research [Internet]. ResearchGate. [cited 2021 Dec 18]. Available from: https://www.researchgate.net/figure/Challenges-in-pharmacogenomics-research_fig2_340513525

114. Salari P, Larijani B. Ethical Issues Surrounding Personalized Medicine: A Literature Review. Acta Med Iran. 2017 Mar;55[3]:209-17.

115. Ethical perspectives on pharmacogenomic profiling in the drug development process | Nature Reviews Drug Discovery [Internet]. [cited 2021 Dec 18]. Available from: https://www.nature.com/articles/nrd771

116. Emerging Ethical Issues in Pharmacogenomics | SpringerLink [Internet]. [cited 2021 Dec 18]. Available from: https://link.springer.com/article/10.2165/00129785-200202040-00007

117. Ethical and legal implications of pharmacogenomics | Nature Reviews Genetics [Internet]. [cited 2021 Dec 18]. Available from: https://www.nature.com/articles/35056075 